\title{
Outsourcing Service Departments
}

\author{
Massoud Malek \\ California State University, California, USA
}

\begin{abstract}
In a manufacturing company, certain departments can be characterized as production departments and others as service departments. This paper expands and simplifies the results by the author and his co-author (Lowenthal \& Malek, 2005; 2013), by explaining in a simple way how to obtain the fair-price per unit to pay to external suppliers that replace service departments. The paper also proves that replacing several service departments at once produces exactly the same fair-price per unit if they were replaced sequentially.
\end{abstract}

Keywords: service departments, production department, outsourcing, external supplier, traceable cost, full cost, fair value cost per unit, indifference point

\section{Introduction}

In a manufacturing company, certain departments can be characterized as production departments and others as service departments. Examples of service departments are purchasing, computing services, repair and maintenance, security, food services, etc.. The costs of such service departments must be allocated to the production departments, which in turn will allocate them to the product.

Through an elementary example, Kaplan (1973) found a fair value of service provided by an outside supplier for a single service department. Kaplan asserted that were the $j^{\text {th }}$ service department eliminated and an external supplier contracted to perform this identical service, then paying this external supplier exactly $u_{j}$ per unit of service will lead to the same total cost to the firm as it presently incurs. Thus, this cost per unit represents the indifference point as far as accepting the actual bid of an external supplier.

The one that we examine in this paper simply attacks the problem by finding a linear system of $m$ equations in $m$ unknowns to find the true or full cost of each service department and then allocating these costs directly to the production departments (Taha, 1992; Winston, 1994).

\section{Definitions, Notations, and Example}

Throughout this paper, we shall assume that there are $m$ service departments and $n$ production departments, where some service departments may exclusively serve service departments. However, if a block of $r(1 \leq r \leq m)$ service departments serves among itself, then at least one member of this block must service some production departments or at least one service department outside of the block.

In all that follows, the $n \times n$ identity matrix is denoted by $I_{n}$. We also make the following assumptions (Markland, 1989; Schmidt, 1974):

(1) All service department costs are strictly variable and there is no fixed cost involved (i.e., $c(x)=u x$, where $u$ represents the unit cost and $x$ the number of units);

Massoud Malek, professor of Mathematics, California State University. Email: massoud.malek@csueastbay.edu. 
(2) The amount of the total cost originally allocated to the service departments must remain the same;

(3) The external supplier will absorb any self-service requirements.

We illustrate the problem with the following example found in Lowenthal and Malek (2005; 2013) using some of the results about matrices found in Horn and Johnson (1985).

\section{Example}

Algebra Inc. has four service departments (S1, S2, S3, and S4) and three production departments (P1, P2, and P3). Direct costs of $\$ 78,000$ for S1, $\$ 200,000$ for S2, $\$ 100,000$ for S3, and $\$ 150,000$ for S4 are to be allocated to P1, P2, and P3 by the linear algebra reciprocal service method in accordance with the figures given in Table 1.

Table 1

Algebra Inc.

\begin{tabular}{lllll}
\hline Department & S1 & S2 & S3 & S4 \\
\hline S1 & 40 & 200 & 500 & 100 \\
S2 & 160 & 100 & 200 & 100 \\
S3 & 400 & 100 & 300 & 100 \\
S4 & 200 & 0 & 1,000 & 100 \\
P1 & 1,800 & 600 & 2,000 & 1,600 \\
P2 & 400 & 600 & 2,000 & 2,000 \\
P3 & 1,000 & 2,000 hours & 4,000 & 1,000 \\
Total units & 4,000 employees & $\$ 200,000$ & 10,000 square feet & 5,000 calls \\
Traceable cost & $\$ 78,000$ & $\$ 100.00$ & $\$ 100,000$ & $\$ 150,000$ \\
Unit cost & $\$ 19.50$ & $\$ 10.00$ & $\$ 30.00$ \\
\hline
\end{tabular}

Note. S1 = Service department 1; S2 = Service department 2; S3 = Service department 3; S4 = Service department 4; $\mathrm{P} 1$ = Production department 1; P2 = Production department 2; P3 = Production department 3.

From Table 1, we denote the following matrices and vectors:

$$
\text { The } 4 \times 4 \text { matrix } S=\left(s_{i j}\right)=\left[\begin{array}{llll}
40 & 200 & 500 & 100 \\
160 & 100 & 200 & 100 \\
400 & 100 & 300 & 100 \\
200 & 0 & 1000 & 100
\end{array}\right]
$$

where $s_{i j}$ is the number of units provided by the service department $j$ to the production department $i$ : This matrix will change, every time a service department is replaced by an external supplier.

$$
\text { The } 3 \times 4 \text { matrix } P=\left(p_{k j}\right)=\left[\begin{array}{cccc}
1800 & 400 & 2000 & 1600 \\
400 & 600 & 2000 & 1600 \\
1000 & 600 & 4000 & 1000
\end{array}\right]
$$

where $p_{k j}$ is the number of units provided by the service departments $\mathrm{s}_{1}, \mathrm{~s}_{2}, \mathrm{~s}_{3}$, and $\mathrm{s}_{4}$ to the service departments $\mathrm{p}_{1}, \mathrm{p}_{2}$, and $\mathrm{p}_{3}$.

Clearly, the matrix $P$ will always remain_fixed.

$$
\text { The total units vector } Z=[4000 ; 2000 ; 10000 ; 5000]
$$

The $j^{\text {th }}$ component of this total units vector is the number of units provided by the $j^{\text {th }}$ service department. 


$$
\text { The diagonal matrix } Z=\left(z_{j j}\right)=\left[\begin{array}{llll}
4000 & 0 & 0 & 0 \\
0 & 2000 & 0 & 0 \\
0 & 0 & 10000 & 0 \\
0 & 0 & 0 & 5000
\end{array}\right]
$$

This diagonal matrix is obtained from the vector $z$.

$$
\text { The } 4 \times 4 \text { matrix } B=(b i j)=S Z^{-1}=\left[\begin{array}{cccc}
0.01 & 0.10 & 0.05 & 0.02 \\
0.04 & 0.05 & 0.02 & 0.02 \\
0.10 & 0.05 & 0.03 & 0.02 \\
0.05 & 0.00 & 0.10 & 0.02
\end{array}\right]
$$

The above matrix represents the proportion of the $j^{\text {th }}$ service department's output provided to the $i^{\text {th }}$ service department.

$$
\text { The } 4 \times 4 \text { matrix } G=\left(g_{i j}\right)=\left(Z^{-1}\right)^{t} S=\left[\begin{array}{llll}
0.010 & 0.050 & 0.125 & 0.025 \\
0.080 & 0.050 & 0.100 & 0.050 \\
0.040 & 0.010 & 0.030 & 0.010 \\
0.040 & 0.000 & 0.200 & 0.020
\end{array}\right]
$$

where the $j^{\text {th }}$ component of the vector $z G$ is the total number of units provided by the service department $j$ to all service departments, including itself.

\section{Remark}

When the $j^{\text {th }}$ service department is replaced by an external supplier, then the $j^{\text {th }}$ row of the new matrix $G$ denoted by $\widetilde{\boldsymbol{G}}$ will be replaced by the zero vector. Also note that the matrix $I-G$ will always be invertible (see Lowenthal \& Malek, 2013).

$$
\text { The vector } p=z-z G=z\left(I_{4}-G\right)=\left[\begin{array}{llll}
3200 & 1600 & 8000 & 4600
\end{array}\right]
$$

The above vector represents the number of units allocated to the production departments which will remain fixed at anytime.

$$
\text { The vector } b=\left[\begin{array}{llll}
\$ 78,000 & \$ 200,000 & \$ 100,000 & \$ 150,000
\end{array}\right]
$$

The $j^{\text {th }}$ component of the above vector represents the traceable costs of the service department $j$. Clearly, this traceable costs vector must remain constant.

$$
\text { The vector } c=Z^{-1} b=\left[\begin{array}{llll}
\$ 19.50 & \$ 100.00 & \$ 10.00 & \$ 30.00
\end{array}\right]
$$

The above vector represents the traceable costs per unit of the original problem (i.e., no outside sources are involved).

\section{Results}

Based on results obtained in Lowenthal and Malek (2005), one may easily extend the result in this example into a problem with $m$ service and $n$ production departments. 
Our task is to find the "full cost" vectors $v$. Kaplan (1973) commented that the full cost components of the vector $v$ (Render \& Stair, 1982), which clearly must exceed the actual costs of the corresponding component of the traceable vector $b$, have an important economic application; these costs, after being divided by the corresponding quantity of output of the respective department, represent the per unit cost that should be paid to an external supplier of the service currently provided by the service department.

Note that by subtracting the cost of running the service departments from the full cost, we must obtain the traceable cost $b$. Thus:

$$
v-B v=b^{t}=\left[\begin{array}{l}
\$ 78,000 \\
\$ 200,000 \\
\$ 100,000 \\
\$ 150,000
\end{array}\right]
$$

This implies that:

$$
v=\left(I_{4}-B\right)^{-1} b^{t}=\left[\begin{array}{llll}
0.99 & 0.10 & 0.05 & 0.02 \\
0.04 & 0.95 & 0.02 & 0.02 \\
0.10 & 0.05 & 0.93 & 0.02 \\
0.05 & 0.00 & 0.10 & 0.98
\end{array}\right]^{-1}\left[\begin{array}{l}
\$ 78,000 \\
\$ 200,000 \\
\$ 100,000 \\
\$ 150,000
\end{array}\right]=\left[\begin{array}{l}
\$ 111,182.30 \\
\$ 221,554.43 \\
\$ 129,520.58 \\
\$ 171,950.18
\end{array}\right]
$$

The components of the vector $u=v^{t} Z^{-1}=\left[\begin{array}{lllll}\$ 27.80 & \$ 110.77 & \$ 12.95 & \$ 34.39\end{array}\right]$ represent the "full cost" per unit of each service department. Clearly, both the full cost vector $v$ and the "full cost pet unit" $u$ will remain fixed even after replacing some service departments with outside suppliers.

Now if the service department $j$ is replaced by an outside source, then the fair value of each unit in that department is $u_{j}$ which must be paid to the outside supplier taking over the department $j$. Clearly, the value of the unit price of the service department $k$ that is not replaced by an outside source remains $c_{k}$ of the vector:

$$
C=\left[\begin{array}{llll}
\$ 19.50 & \$ 100.00 & \$ 10.00 & \$ 30.00
\end{array}\right]
$$

Suppose now that $r(1 \leq r \leq m)$ service departments are replaced by outside suppliers.

By relabeling some of the service departments, if necessary, we may assume without loss of generality that the first $r$ service departments are replaced by outside suppliers:

$$
\mathrm{O}_{1}, \mathrm{O}_{2}, \ldots, \mathrm{O}_{\mathrm{r}}
$$

We shall prove that $O_{k}(k=1,2, \ldots, r)$ should be paid $u_{k}$ dollars per unit for its services; but first, we need to define the matrix $G_{r, 0}$ by replacing the first $r$ columns of $G$ by zero columns. We have:

$$
G=\left[G_{1}, G_{2}, \ldots, G_{r}, G_{r+1}, \ldots, G_{n}\right] \text { and } G_{r, 0}=\left[0,0, \ldots, 0, G_{r+1}, \ldots, G_{n}\right]
$$

The traceable cost per unit will be:

$$
\check{c}=\left[u_{1}, u_{2}, \ldots, u_{r}, c_{r+1}, c_{r+2}, \ldots, c_{m}\right]
$$


Also:

$$
\check{c} \check{Z}^{t}=p \quad \breve{G}^{-1} \check{Z}=\operatorname{diag}[\check{z}(1), \check{z}(2), \ldots, \check{z}(m)] \text {, and } \check{S}=\check{Z}\left[\begin{array}{c}
G_{r}+1 \\
G_{r}+2 \\
\cdot \\
\cdot \\
G_{m}
\end{array}\right]
$$

From $\check{c}$, we obtain the traceable costs of the service departments $\breve{b}=\check{c} \check{Z}$.

By replacing the first service department with an external supplier, the matrix $\breve{\boldsymbol{G}}_{\mathbf{1}}$ is obtained from $\boldsymbol{G}$ by replacing the first row of the matrix $\breve{\boldsymbol{G}}_{\mathbf{1}}$ with a zero vector. Then from the matrix $\breve{\boldsymbol{G}}_{\mathbf{1}}$, we obtain $\check{\mathbf{Z}}_{\mathbf{1}}, \check{Z}_{\mathbf{1}}, \breve{S}_{1}, \breve{B}_{1}$, and $\check{C}_{1}$, and make Table 2 .

Table 2

The First Service Department is Replaced by an Outside Supplier O1

\begin{tabular}{lllll}
\hline One supplier & O1 & S2 & S3 & S4 \\
\hline S2 & 143 & 89 & 178.35 & 89 \\
S3 & 378 & 94 & 283.13 & 94 \\
S4 & 195 & 0 & 976.23 & 98 \\
P1 & 1,800 & 400 & 2,000 & 1,600 \\
P2 & 400 & 600 & 2,000 & 2,000 \\
P3 & 1,000 & 600 & 4,000 & 1,000 \\
Total units & 3,915 employees & $1,783.55$ hours & $9,437.72$ square feet & 4,881 calls \\
Traceable cost & $\$ 108,832$ & $\$ 178,355.50$ & $\$ 94,377.23$ & $\$ 146,435.36$ \\
Unit cost & $\$ 27.80$ & $\$ 100.00$ & $\$ 10.00$ & $\$ 30.00$ \\
\hline
\end{tabular}

If we replace the first and second service departments with outside suppliers, then we must replace the first and second rows of the matrix $G$ with zero rows; and the first and second components of $c$ with the first and second components of the vector $u$. The resulting matrix and vector are the matrix $e G_{12}$ and the vector $e c_{12}$.

Table 3 represents the replacement of the service departments S1 and S2 with outside suppliers O1 and O2.

Table 3

The First Two Service Departments are Replaced by Two Different Outside Suppliers O1 and O2

\begin{tabular}{lllll}
\hline Two suppliers & O1 & O2 & S3 & S4 \\
\hline S3 & 369 & 92.35 & 277.04 & 92 \\
S4 & 192 & 0 & 957.62 & 96 \\
P1 & 1,800 & 400 & 2,000 & 1,600 \\
P2 & 400 & 600 & 2,000 & 2,000 \\
P3 & 1,000 & 600 & 4,000 & 1,000 \\
Total units & 3,761 employees & $1,692.35$ hours & $9,234.66$ square feet & 4,788 calls \\
Traceable cost & $\$ 104,536.68$ & $\$ 187,473.15$ & $\$ 92,346.60$ & $\$ 143,640.00$ \\
Unit cost & $\$ 27.80$ & $\$ 110.77$ & $\$ 10.00$ & $\$ 30.00$ \\
\hline
\end{tabular}

Now suppose after using an outside supplier for the first service department, we also replace the second service department by an outside supplier. Then, we must replace the second row of $e \boldsymbol{G}_{1}$ with a zero vector, and the second component of $e \boldsymbol{c}_{1}$ with $\boldsymbol{u}(2)$. This clearly produces exactly the same matrix $e \boldsymbol{G}_{12}$ and the vector $e \boldsymbol{c}_{12}$ and the same table as the above. 
Table 4

The First Three Service Departments are Replaced by Three Different Outside Suppliers O1, O2, and O3

\begin{tabular}{lllll}
\hline Three suppliers & O1 & O2 & O3 & S4 \\
\hline S4 & 188 & 0 & 938.78 & 94 \\
P1 & 1,800 & 400 & 2,000 & 1,600 \\
P2 & 400 & 600 & 2,000 & 2,000 \\
P3 & 1,000 & 600 & 4,000 & 1,000 \\
Total units & 3,388 employees & 1,600 hours & $8,938.78$ square feet & 4,881 calls \\
Traceable cost & $\$ 94,164.60$ & $\$ 177,243.54$ & $\$ 115,775.53$ & $\$ 140,816.32$ \\
Unit cost & $\$ 27.80$ & $\$ 110.77$ & $\$ 12.95$ & $\$ 30.00$ \\
\hline
\end{tabular}

Table 5

All the Service Departments are Replaced by Outside Suppliers O1, O2, O3, and O4

\begin{tabular}{lllll}
\hline Four suppliers & O1 & O2 & O3 & O4 \\
\hline P1 & 1,800 & 400 & 2,000 & 1,600 \\
P2 & 400 & 600 & 2,000 & 2,000 \\
P3 & 1,000 & 600 & 4,000 & 1,000 \\
Total units & 3,200 employees & 1,600 hours & 8,000 square feet & 4,600 calls \\
Traceable cost & $\$ 88,946$ & $\$ 177,243.54$ & $\$ 103,616.46$ & $\$ 158,194$ \\
Unit cost & $\$ 27.80$ & $\$ 110.77$ & $\$ 12.95$ & $\$ 34.39$ \\
\hline
\end{tabular}

Tables 4 and 5 above represent the replacement of the first three service departments and the replacement.

Note that in the above tables, the product of the fair value per unit vector $\boldsymbol{e} c$ by the total unit vector $\boldsymbol{e} z$ is always $\$ 528.000$ which is exactly the same as $c z^{t}$.

\section{Conclusion}

In our example, if the service departments are replaced by outside suppliers, then the company must pay $u_{1}=\$ 27.80$ per unit to the supplier O1, whether the other service departments are replaced by outside suppliers or not. Similarly, the company must pay $u_{2}=\$ 110.77$ per unit to the supplier O2, and so on. But we should note that the full cost per unit vector and the costs of service departments allocated to each production department remain intact. Also, the total cost $T=\$ 528,000$ will remain the same.

\section{References}

Horn, R. A., \& Johnson, C. A. (1985). Matrix analysis. Cambridge: Cambridge University Press.

Kaplan, R. S. (1973). Variable and self-service costs in reciprocal allocation models. The Accounting Review, 48(4), 738-748.

Lowenthal, F., \& Malek, M. (2005). Reciprocal service department cost allocation and decision making. Journal of Applied

Mathematics and Decision Sciences, 3, 137-147.

Lowenthal, F., \& Malek, M. (2013). Cost allocation for outside sources replacing service departments. Applied Mathematical Sciences, 7(26), 1263-1273.

Markland, R. E. (1989). Topics in management science (3rd ed.). New York, NY: John Wiley \& Sons.

Render, B., \& Stair, R. M. (1982). Quantitative analysis for management. Allyn \& Bacon, Inc..

Schmidt, J. W. (1974). Mathematical foundations for management science and systems analysis. New York, NY: Academic Press.

Taha, H. A. (1992). Operations research: An introduction. New York, NY: McMillan.

Winston, W. L. (1994). Operations research: Applications and algorithm (3rd ed.). Belmont, CA: Duxbury Press. 